\title{
Design Study of a 50-kA React-and-Wind Bi-2212 Cable for Fusion Magnet
}

\author{
Rui Kang, Davide Uglietti, Yuntao Song
}

\begin{abstract}
In the last few years the current density of Bi-2212 wires has been greatly improved by filament densify technologies. One further step toward applications in fusion magnets is to design a high current cable, which must overcome the drawbacks of $\mathrm{Bi}-2212$ wire: brittleness and complex heat treatment process. In this paper, React-and-Wind flat cables are proposed. With react-and-wind technique, a larger choice of jacket and stabilizer materials are available including stainless steel and copper, which are widely used for superconducting cables but are not directly usable for Wind-and-React $\mathrm{Bi}-2212$ cables due to their reaction during heat treatment. Two wires, representing respectively bottom and top performance of state-of-art wires, are considered. Several cable layouts are studied considering dimension, compaction rate and transverse mechanical pressure. Materials for quench protection and jacket materials are also discussed.
\end{abstract}

Index Terms-Bi-2212, React-and-Wind, Wind-and-React, Cable-in-conduit conductor, high temperature superconductor

\section{INTRODUCTION}

A mong practical high temperature superconducting (HTS) materials, $\mathrm{Bi}_{2} \mathrm{Sr}_{2} \mathrm{CaCl}_{2} \mathrm{O}_{8+\delta}(\mathrm{Bi}-2212$.) is the only one that can be manufactured into round and rectangular wires with isotropic properties. Therefore it has been attracting interests in high field application for over 30 years. However, Bi-2212 had long suffered from the unreliable performance of long length wires, whose critical current density in the superconducting ceramic $\left(J_{c}\right)$ is often lower than in short samples. The interest of Bi-2212 was revived after an increase of about one order of magnitude in $J_{c}$ thanks to the OverPressure-Heat-Treatment (OPHT) technology $[1,2]$.

Another drawback of Bi-2212 wire is its brittleness and low strength. Bi-2212 wires are usually made by powder-in-tube technology, with silver matrix and silver alloy sheath. Typical limits in longitudinal tensile strain are between $0.3 \%$ and $0.6 \%$; the corresponding longitudinal stress limit is less than $100 \mathrm{MPa}$, as is reviewed in section II.C.

Considering the strain limitation, one may prefer a Windand-React (W\&R) conductor for Bi-2212, as in the case of $\mathrm{Nb}_{3} \mathrm{Sn}$ conductor for ITER magnet [3], which is also brittle and sensitive to strain. A W\&R Bi-2212 conductor prototype was prepared by Qin et al [4] for fusion magnet. Godeke et al also proposed a W\&R Rutherford cable for accelerator magnet about ten years ago [5]. However, in DEMO reactors the magnets are typically larger then in ITER, making the heat

R. Kang is with the Department of Engineering and Applied Physics, University of Science and Technology of China, Hefei 230026, China. (Email: kangrui@mail.ustc.edu.cn). R. Kang is now a visiting student at EPFL Swiss Plasma Center, Villigen PSI, Switzerland. treatment of the whole magnet even more challenging, not to mention with the OPHT. One more complication is that few alloys are compatible with the oxygen atmosphere during the high temperature heat treatment $[4,6,7]$, limiting the choice of jacket material or requiring an extra metallic layer between the cable and the jacket. The choice of materials for quench protection is also limited for the same reason. Therefore one of the advantages of the React-and-Wind (R\&W) technique is that it would allow much larger choices of structural, quench protection and insulating materials. R\&W technology was already demonstrated in common coil dipoles (Bi2212 Rutherford cable) at Brookhaven [8]. Swiss Plasma Center recently tested a flat $\mathrm{R} \& \mathrm{~W} \mathrm{Nb} \mathrm{N}_{3} \mathrm{Sn}$ cable for EU-DEMO $[9,10]$.

The feasibility of a flat R\&W Bi-2212 cable for the central solenoid (CS) magnet of China Fusion Engineering Test Reactor (CFETR) Phase II is studied in this paper. The available strain range for bending and $J_{c}$ at $4.2 \mathrm{~K}$ is estimated according to the published data for Bi2212 wires. On these basis, several kinds of cable layout are compared considering the cable thickness and width, compaction rate, strand diameter and transverse pressure. A scaling law of $J_{c}$ as function of temperature and magnetic field was used to study stability and quench behavior. At last, jacket material options are discussed according to their thermal contraction.

\section{Review of $\mathrm{J}_{\mathrm{c}}(\mathrm{B}, \mathrm{T}, \varepsilon)$ in $\mathrm{Bi} 2212$ wires}

\section{A. Current density}

The formation of gas bubbles in the ceramic during heat treatment is the reason of the poor performance of long Bi2212 wires. If the gas bubble formation is prevented by densifying the superconducting filaments, $J_{c}$ can be increased by almost one order of magnitude [2, 11]. Several densifications methods have been developed. Cold isostatic pressure (CIP) and swaging are applied after drawing but prior to heat treatment [11]. Densification can be applied before heat treatment by groove-rolling, and was later developed as GDG (groove-rolling/drawing/groove-rolling) process [12-14]. OPHT is used alone or in combination with the previous methods. A very high $J_{c}$ of $6860 \mathrm{~A} / \mathrm{mm}^{2}$ at $4.2 \mathrm{~K}$ and $15 \mathrm{~T}$ was reported [15]. New purer precursor powders are also contributing to the improvement in critical current density, because the reduction in the amount of volatile impurities limit the gas bubbles formation [15].

D. Uglietti is with the EPFL Swiss Plasma Center, Villigen PSI, Switzerland (E-mail: davide.uglietti@psi.ch).

Y. Song is with the Department of Institute of Plasma Physics, Chinese Academy of Sciences, Hefei 230031, China. (E-mail: songyt@ipp.ac.cn). 
TABLE I

WiRE CONFIGURATION For DATA In FIG. 1

\begin{tabular}{lllll}
\hline \hline Reference & Powder Supplier & $\varnothing(\mathbf{m m})$ & Fill factor & Densify method \\
\hline 2001, Hasegawa [16] & Nexans & 0.81 & $25 \%$ & No \\
2009, Rey [17] & 0.8 & $10.5 \%$ & No \\
2011, Lombardo [18] & Nexans & 0.8 & $26 \%$ & No \\
2014, Huang [11] & Nexans & 1.2 & $23 \%$ & No \\
2014, Huang [11] & Nexans & 1.2 & $23 \%$ & CIP at $690 \mathrm{MPa}$ \\
$\mathbf{2 0 1 4}$, Huang [11] & Nexans & 1.2 & $23 \%$ & CIP + $10 \mathrm{bar}$ OP \\
2014, Larbalestier [1] & Nexans & 0.8 & $23.4 \%$ & 100 bar OP \\
2016, Zhang [19] & nGimat & 0.81 & $12 \%$ & 100 bar OP \\
2016, Leveratto [13] & Nexans & $0.7 \times 0.7$ (square) & $18 \%$ & GDG \\
2017, Jiang [15] & nGimat & 0.78 & $20 \%$ & 50 bar OP \\
2017, Jiang [15] & Nexans & $0.8-1.0$ & $19.6 \%$ & 50 bar OP \\
2018, Liu [20] & NIN & 1.0 & $24.3 \%$ & 50 bar OP \\
\hline \hline
\end{tabular}

\section{B. Dependence of $J_{c}$ on magnetic field and temperature}

The improvement in critical current density of Bi-2212 wires with the employment of filaments-densify technologies is almost one order of magnitude. Fig. 1 shows some published data of magnetic field dependence of $J_{c}$ at $4.2 \mathrm{~K}[2,11,13,15-$ 20] (data in [14] was first presented in EUCAS 2017). The characteristics of the Bi-2212 wires used in these experiments are summarized in Table I. Some of the original data are given in the form of critical current or critical current density of wire, but the corresponding $J_{c}$ (current density in the superconducting ceramic) have been calculated and compared here. For all of these wires, the field dependence of $J_{c}$ at $4.2 \mathrm{~K}$ appears very similar, despite the differences in the manufacturing processes.

The scaling law of $J_{c}$ for Bi-2212 is obtained by fitting the data reported by Lombardo et al [18] with the scaling relation shown in Eq. (1-3). The fitting parameters are shown in Table II. It should be stressed that $B_{s c 0}$ and $T_{s c}$ are constants for all wires and only the parameter $A$ changes with different wires; in this paper two values of $A$ are considered representing two

Table II

SCALING PARAMETERS For $\mathrm{J}_{\mathrm{C}}$

\begin{tabular}{ccccccccc}
\hline \hline $\mathbf{p}$ & $\mathbf{q}$ & $\boldsymbol{\alpha}$ & $\boldsymbol{\mu}$ & $\begin{array}{c}\mathbf{B}_{\text {sc0 }} \\
{[\mathbf{T}]}\end{array}$ & $\boldsymbol{\beta}$ & $\boldsymbol{v}$ & $\begin{array}{c}\mathbf{A} \\
{\left[\mathbf{N} \cdot \mathbf{T}^{-\mathbf{v}}\right]}\end{array}$ & $\begin{array}{c}\mathbf{T}_{\text {sc }} \\
{[\mathbf{K}]}\end{array}$ \\
\hline $\mathbf{0 . 8 8 5}$ & 4 & 1.02 & 10 & 307 & 1.59 & 1.24 & $408 / 1836$ & 95 \\
\hline \hline
\end{tabular}

$$
\begin{gathered}
B_{s c}(T)=B_{s c 0}\left(1-\left(\frac{T}{T_{s c}}\right)^{\alpha}\right)^{\mu} \\
F_{p 0}(T)=A\left(1-\left(\frac{T}{T s c}\right)^{\beta}\right) B_{s c}(T)^{v} \\
J_{c}(B, T)=\frac{F_{p 0}(T)}{B}\left(\frac{B}{B_{s c}(T)}\right)^{p}\left(1-\left(\frac{B}{B_{s c}(T)}\right)\right)^{q}
\end{gathered}
$$

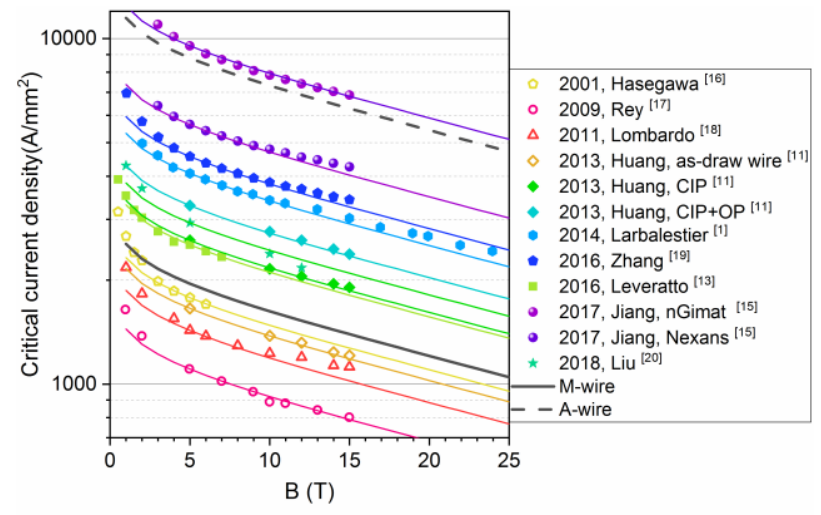

Fig. 1 Relation of $\mathrm{J}_{\mathrm{c}}$ and $\mathrm{B}$ at $4.2 \mathrm{~K}$ from published data. Open symbols are for measurement data of non-densified wires, filled symbols are for data of densified wires. Lines are for fitting data using the scaling law shown in Eq. 1-3 (only the parameter A is changed for different wires.) The hypothetical A-wire and $\mathrm{M}$-wire used in the later sections are also shown. The fitting lines are shown up to $25 \mathrm{~T}$.

hypothetical wires as later explained in section III.A. Although the temperature dependence varies among samples, especially at higher temperature $[17,18,21,22]$, the scaling law above with the same set of parameters (see table II) is still valid for all samples at least at temperatures $<30 \mathrm{~K}$, which is of interest for the cable design. Due to the lack of data at high temperature or at low temperature and high field $(>25 \mathrm{~T})$, this scaling law should be cautiously used in those conditions.

\section{C. $J_{c}$-Strain Relation}

The model for $J_{c}$-strain behavior has been proposed by tenHaken et al, which was further improved by Cheggour et al [23-33]. According to this model, $J_{c}$ will immediately degrade irreversibly in longitudinal compression at almost constant rate. In longitudinal tension, there is a range of slight reversible decrease of $J_{c}$; after that, $J_{c}$ will degrade irreversibly very fast. This reversible limit, according to various published data, is between $0.3 \%$ and $0.6 \%$ for the state-of-art wires.

To design an $\mathrm{R} \& \mathrm{~W} \mathrm{Bi}-2212$ conductor, the first step is to identify the strain range which can be tolerated without resulting in too much $J_{c}$ degradation. Although for a free standing Bi-2212 wire there is only very narrow strain range in which there is no irreversible $J_{c}$ degradation, several 
experiments have verified that for both tension and compression, after $\mathrm{J}_{\mathrm{c}}$ irreversibly decreased, a new longer reversible range is established. In addition, the $\mathrm{J}_{\mathrm{c}}$-strain relation is independent on magnetic field [29, 30, 33]. A sufficient large strain range (and thus corresponding bending radius) is then available if some $J_{c}$ is sacrificed. In fact, according to tenHaken [25], the reversible plateau in tension is no other than a result of thermal induced compression owing to the different thermal contraction of $\mathrm{Bi}-2212$ ceramic and $\mathrm{Ag}$ alloy during cooling down from heat treatment temperature: this means that the $J_{c}$ of a virgin wire after heat treatment is already degraded irreversibly, as shown in Fig. 2 (see also Fig. 2 in [25]). $\mathrm{J}_{\mathrm{c}}$ of a strain free wire (if the matrix has exactly the same thermal contraction with $\mathrm{Bi}-2212$ ceramic) will immediately degrade irreversibly once it is put under tension or compression (dashed line in fig. 2 left).

Fig. 2 (left) shows the strain dependence of $\mathrm{J}_{\mathrm{c}}$ in both tension and compression. The data are from [27-30, 33] and the characteristics of the $\mathrm{Bi}-2212$ wires used in these experiments are summarized in Table III. It should be noted that in the measurements of Dai et al and Godeke et al, the Ti-6Al-4V spring brings about $0.3 \%$ pre-tension to the test sample when cooling down from soldering temperature to $4.2 \mathrm{~K}$. This pretension has been accounted for in Fig 2. $\mathrm{J}_{\mathrm{c}}$ starts to decreases rapidly at strain higher than $0.4 \%$. Thus $0.4 \%$ of tension should be the ultimate limit to be considered in the cable design.

In compression the critical strain is basically $0 \%$, but it can be extended if some degradation of $\mathrm{J}_{\mathrm{c}}$ is accepted. As shown in Fig. 2, with a compression of $-0.4 \%$, the degradation of $J_{c}$ is between $10 \%$ and $20 \%$. Thus, even a conservative estimation of $20 \%$ degradation at $-0.4 \%$ compression would result in a $0.8 \%$ strain range (form $-0.4 \%$ to $0.4 \%$ ), which should be sufficient for R\&W conductor design. As comparison, Fig. 2 (left) also shows the $\mathrm{J}_{\mathrm{c}}$-strain relation for $\mathrm{Nb}_{3} \mathrm{Sn}$ (intrinsic) (data from [34]). Unlike HTS materials, $\mathrm{J}_{c}(\varepsilon)$ of $\mathrm{Nb}_{3} \mathrm{Sn}$ strongly depends on magnetic field, so the relation at $15 \mathrm{~T}$, which is in the field range of interest $(15 \mathrm{~T}-20 \mathrm{~T})$ is plotted. Bi-2212 wire shows less $\mathrm{J}_{\mathrm{c}}$ degradation than $\mathrm{Nb}_{3} \mathrm{Sn}$ in the strain range of interest, but the difference is that in $\mathrm{Nb}_{3} \mathrm{Sn}$ the

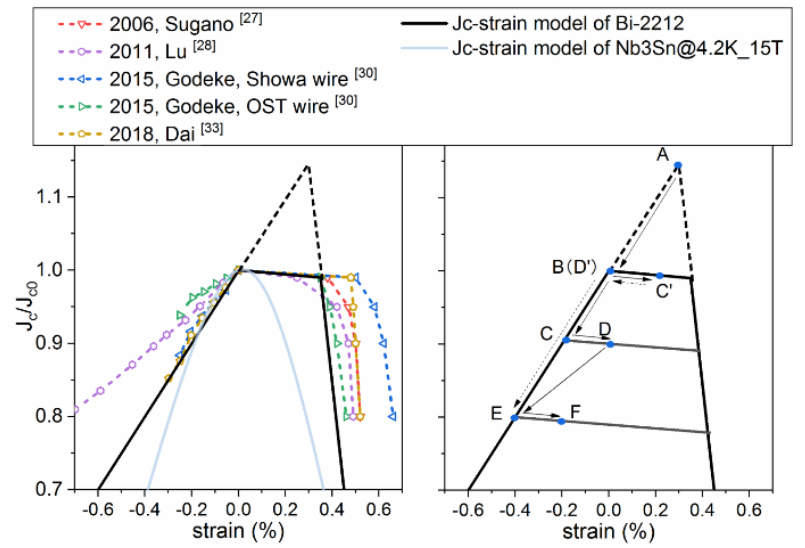

Fig. 2 The left figure shows Jc-strain relation for Bi-2212 wires from published data. Typical relation for $\mathrm{Nb3Sn}$ is also given as comparison. All data are measured at low temperature ( $4.2 \mathrm{~K}$ or $6 \mathrm{~K})$. The right figure is a sketch of the variation of Jc and strain during an R\&W coil fabrication. Dash lines connect C', D' and E.

reduction of $\mathrm{J}_{\mathrm{c}}$ is reversible, while in $\mathrm{Bi}-2212$ is not. On the other hand, in both cases the reduction is permanent when the wires are used in magnets.

Since in the $\mathrm{R} \& \mathrm{~W} \mathrm{Nb} \mathrm{Nb}_{3} \mathrm{Sn}$ conductor [35], the strain range during transportation, winding, operation is between $-0.4 \%$ and $+0.1 \%$, it is reasonable to consider $\mathrm{R} \& \mathrm{~W}$ also for a $\mathrm{Bi}$ 2212 conductor which shows better performance against strain than $\mathrm{Nb}_{3} \mathrm{Sn}$. The strain evolution during a hypothetical fabrication process of a CS coil is reported in Fig. 2 (right):

1) $\mathrm{A} \rightarrow \mathrm{B}$ : React the cable on the same diameter of the final coil and then cool down to room temperature (RT). Part of $\mathrm{J}_{\mathrm{c}}$ is lost as a result of the different thermal contraction of $\mathrm{Bi}-2212$ ceramic and $\mathrm{Ag}$ alloy. The strain state at RT is then set as $0 \%$.

2) $B \rightarrow C / C^{\prime}:$ Straighten the cable, and jacketing. Now the strain in the cable is between $-\varepsilon_{b}$ (point $C$ ) and $+\varepsilon_{b}$ (point $\mathrm{C}^{\prime}$ ) and $\mathrm{J}_{\mathrm{c}}$ is reduced for the strands in the compressive region.

TABLE III

Wire CONFIGURATION AND TEST CONDITION For DATA In Fig. 2

\begin{tabular}{|c|c|c|c|c|c|}
\hline Reference & 2006, Sugano [27] & 2011, Lu [28] & $\begin{array}{l}\text { 2015, Godeke } \\
{[30]}\end{array}$ & $\begin{array}{l}\text { 2015, Godeke } \\
{[30]}\end{array}$ & 2018, Dai [33] \\
\hline Filament Configuration & $61 \times 7$ & $85 \times 7$ & $61 \times 7$ & $37 \times 18$ & $19 \times 18$ \\
\hline Matrix \& Sheath & $\mathrm{Ag} / \mathrm{Ag}-\mathrm{Mg}-\mathrm{Cu}$ & $\mathrm{Ag} / \mathrm{Ag}-\mathrm{Mg}$ & $\mathrm{Ag}-\mathrm{Mg}-\mathrm{Sb}$ & $\mathrm{Ag} / \mathrm{Ag}-\mathrm{Mg}$ & $\mathrm{Ag} / \mathrm{Ag}-\mathrm{Mg}$ \\
\hline Wire Supplier & Showa & OST & Showa & OST & NIN \\
\hline Diameter (mm) & 0.8 & $0.8-1.0$ & 0.8 & 0.8 & 1 \\
\hline Fill Factor & $21 \%$ & $25-30 \%$ & $33 \%$ & $25 \%$ & $24.30 \%$ \\
\hline Densify Method & None & None & OPHT & OPHT & None \\
\hline Test Condition & $\begin{array}{l}6 \mathrm{~K}, 8 \mathrm{~K} \text { and } 10 \mathrm{~K} ; 20 \\
\text { and } 30 \mathrm{~T}\end{array}$ & $\begin{array}{l}4 \mathrm{~K} \\
5 \mathrm{~T} \text { to } 15 \mathrm{~T}\end{array}$ & $\begin{array}{l}4.2 \mathrm{~K} \\
5 \mathrm{~T} \text { and } 15 \mathrm{~T}\end{array}$ & $\begin{array}{l}4.2 \mathrm{~K} \text {; } \\
5 \mathrm{~T} \text { and } 15 \mathrm{~T}\end{array}$ & $\begin{array}{l}4.22 \mathrm{~K} \\
14 \mathrm{~T}\end{array}$ \\
\hline $\begin{array}{l}\text { Sample Holder Material } \\
\text { (Thermal Contraction mismatch) }\end{array}$ & $\begin{array}{l}\mathrm{Cu}-2 \mathrm{wt} \% \mathrm{Be} \\
(<0.01 \%)\end{array}$ & $\begin{array}{l}\mathrm{Cu}-2 \mathrm{wt} \% \mathrm{Be} \\
(<0.01 \%)\end{array}$ & $\begin{array}{l}\text { Ti-6Al-4V } \\
(+0.3 \%)\end{array}$ & $\begin{array}{l}\text { Ti-6Al-4V } \\
(+0.3 \%)\end{array}$ & $\begin{array}{l}\text { Ti-6Al-4V } \\
(+0.3 \%)\end{array}$ \\
\hline
\end{tabular}


3) $\mathrm{C} / \mathrm{C}^{\prime} \rightarrow \mathrm{D} / \mathrm{D}^{\prime}$ : coil winding. The strain state at RT is now the initial one (about $0 \%$ ), but $\mathrm{J}_{\mathrm{c}}$ is lower at the compression side in step 2 .

4) $\mathrm{D} / \mathrm{D}$ ' $\rightarrow \mathrm{E}$ : Cool down to operating temperature. The strain state is now usually compressive due to the difference of thermal contraction between cable and jacket, assuming $-\varepsilon_{\text {th }}$. $\mathrm{J}_{\mathrm{c}}$ could be further reduced because of the additional thermal compression. And if $-\varepsilon_{\mathrm{th}}<-\varepsilon_{\mathrm{b}}$, all the wires in the cable will have same degraded $J_{c}$.

5) $\mathrm{E} \rightarrow \mathrm{F}$ : Energize the magnet, which introducing tensile strain $\varepsilon_{\mathrm{e}}$ (hoop strain). The strain state is eventually $-\varepsilon_{\mathrm{th}}+\varepsilon_{\mathrm{e}}$.

In Fig. 2 (right), as an example, $\varepsilon_{\mathrm{b}}$ is set at $0.2 \%,-\varepsilon_{\text {th }}$ is set at $-0.4 \%$, عe is set at $0.2 \%$. In such case, the maximum compressive strain controls the final critical current $\left(\mathrm{I}_{\mathrm{c}}\right)$ of the cable. On the other hand, since $\mathrm{J}_{\mathrm{c}}$ degrade very fast once tension exceeds the tensile critical limit, any additional tension could lead to considerable $\mathrm{J}_{\mathrm{c}}$ degradation. Therefore, it's better to keep a sufficient margin from the tensile limit.

The limitation on the cable width from in-plane bending at vertical turn-turn cross over are discussed in III. D.

\section{OVERVIEW OF CABLE CONFIGURATIONS}

With the above background, it is possible to start the design study of an R\&W conductor for the central solenoid of CFETR Phase II, whose design objective is to generate a large magnetic flux in the plasma while keeping the magnet volume as small as possible. A cable that could achieve this goal should have the following characteristics [36]: operating current $\mathrm{I}_{\mathrm{op}}=50 \mathrm{kA}$; operating temperature $\mathrm{T}_{\mathrm{op}}=4.5 \mathrm{~K}$ (temperature margin $>2 \mathrm{~K}$ ) and peak magnetic field $\mathrm{B}_{\max }=17 \mathrm{~T}$.; inner radius $\left(\mathrm{R}_{\mathrm{in}}\right)$ is set at $1 \mathrm{~m}$.

\section{A. Operating current of Bi-2212 wire}

It is premature to choose one value for the current density of Bi-2212, since $\mathrm{J}_{\mathrm{c}}$ of Bi-2212 can vary a lot depending on the fabrication method, as shown in Fig. 1, Consequently, two hypothetical wires with different levels of $\mathrm{J}_{\mathrm{c}}$ at $4.5 \mathrm{~K}$ and $17 \mathrm{~T}$ are considered: one (called $\mathrm{M}$-wire, $\mathrm{M}$ for moderate) with $\mathrm{J}_{\mathrm{c}}$ of $1317 \mathrm{~A} / \mathrm{mm}^{2}$ ) which is achieved by all the densification methods; one (called A-wire, A for ambitious) with $\mathrm{J}_{\mathrm{c}}$ of $5927 \mathrm{~A} / \mathrm{mm}^{2}$, representing the uppermost boundary. The superconducting fraction is conservatively set at $20 \%$ for both wires, resulting in engineering current densities $\left(\mathrm{J}_{\mathrm{e}}\right)$ at $4.5 \mathrm{~K}$ and $17 \mathrm{~T}$ of $263 \mathrm{~A} / \mathrm{mm}^{2}$ and $1185 \mathrm{~A} / \mathrm{mm}^{2}$ respectively. It is

Table IV

CONFIGURATIONS FOR BI-2212 REACT-AND-WIND FLAT CABLE

\begin{tabular}{|c|c|c|c|}
\hline Cable Configuration & $\begin{array}{c}\text { Void fraction } \\
\text { before compaction }\end{array}$ & $\begin{array}{l}\text { Reduction of Cable envelope } \\
\text { with compaction rate of } 85 \%\end{array}$ & $\begin{array}{l}\text { Sketch of cross section } \\
\text { before compaction }\end{array}$ \\
\hline Rutherford cable & $\sim 22 \%$ & $\sim 8 \%$ & 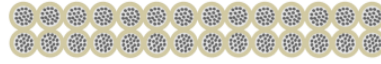 \\
\hline $\begin{array}{l}\text { 2-layers Rutherford } \\
\text { cable }\end{array}$ & $\sim 22 \%$ & $\sim 8 \%$ & 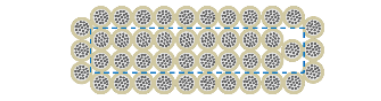 \\
\hline $\begin{array}{c}\text { Roebel bar (strand aspect } \\
\text { ratio }=2)\end{array}$ & & & 56 \\
\hline \multicolumn{4}{|l|}{$\begin{array}{l}\text { Roebel bar }(\text { strand } \\
\text { aspect ratio }=3 \text { ) }\end{array}$} \\
\hline \multicolumn{4}{|l|}{$\begin{array}{l}\text { 2-layers Roebel bar } \\
(\text { strand aspect ratio =2) }\end{array}$} \\
\hline $\begin{array}{l}\text { Rutherford cable } \\
\text { (pair sub-cable) }\end{array}$ & $\sim 61 \%$ & $\sim 54 \%$ & 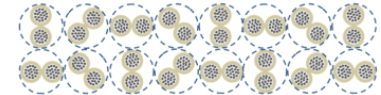 \\
\hline $\begin{array}{l}\text { Rutherford cable } \\
\text { (triplet sub-cable) }\end{array}$ & $\sim 49 \%$ & $\sim 40 \%$ & 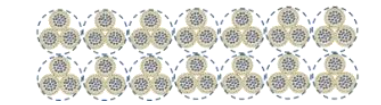 \\
\hline $\begin{array}{l}\text { Rutherford cable } \\
\text { (3x3 sub-cable) }\end{array}$ & $\sim 67 \%$ & $\sim 61 \%$ & \\
\hline $\begin{array}{l}\text { Rutherford cable } \\
\text { (6-around-1 sub-cable) }\end{array}$ & $\sim 48 \%$ & $\sim 39 \%$ & \\
\hline
\end{tabular}



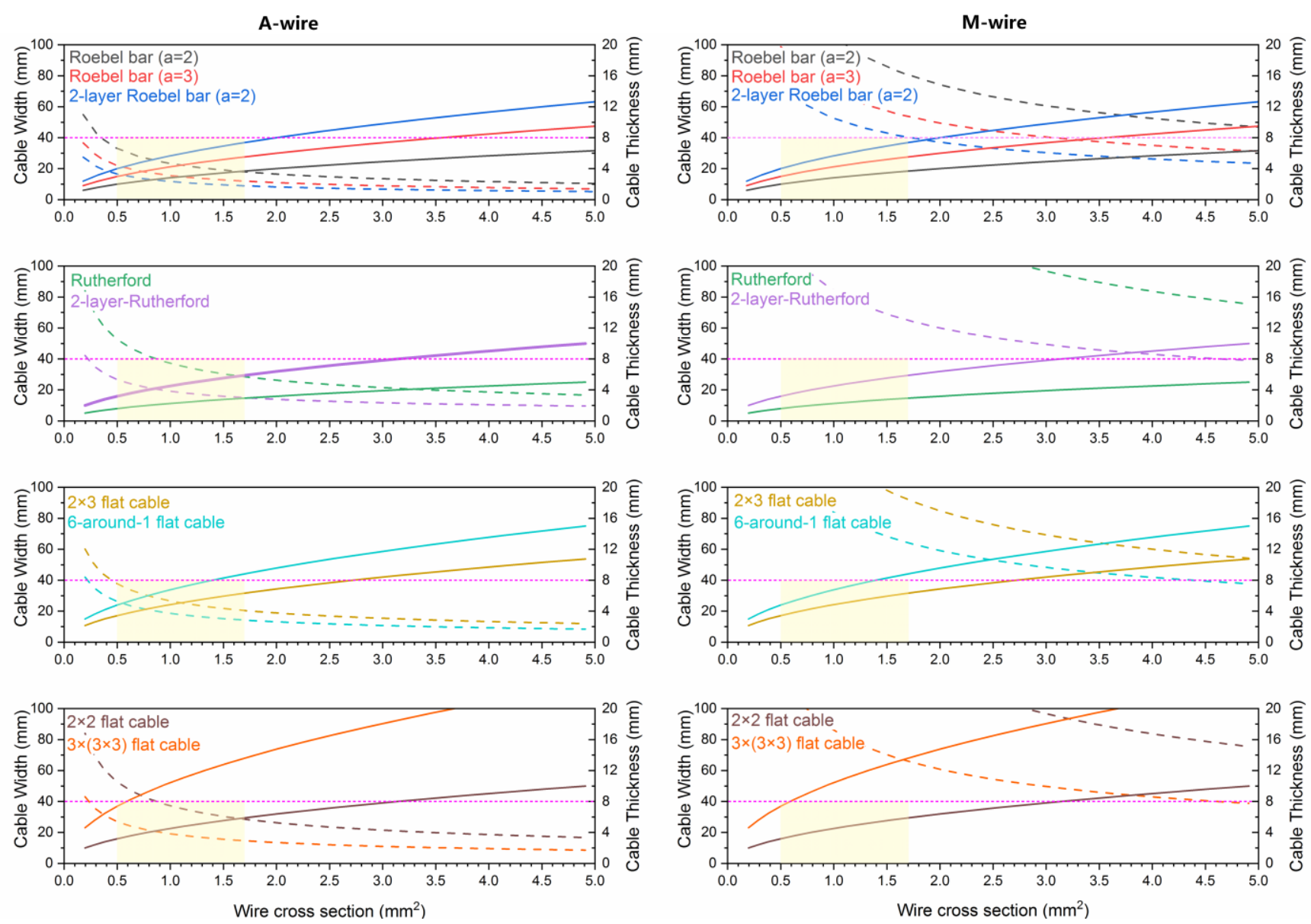

Fig. 3 Cable width (dash lines) and thickness (solid lines) for different configurations as function of wire cross section (a is aspect ratio of rectangular wires) for a $50 \mathrm{kA}$ cable at $17 \mathrm{~T}$. The left figures are with A-wires and right figures are with $\mathrm{M}$-wires. The cable configurations are sorted into 4 groups according to the void fraction. The color of the label is corresponding to the line. The translucent-yellow region shows the typical range of wire cross section (corresponding to 0.8 to $1.5 \mathrm{~mm}$ round wires). The magenta dot line shows the upper limit for both cable width $(40 \mathrm{~mm})$ and thickness $(8 \mathrm{~mm})$ for a winding with radius of $1 \mathrm{~m}$.

assumed that $\mathrm{J}_{\mathrm{c}}$ of $\mathrm{Bi}-2212$ is first reduced by $20 \%$ because of the $-0.4 \%$ strain; then another $20 \%$ is taken as margin for operating current $\left(\mathrm{J}_{\mathrm{op}}\right)$, resulting in a current sharing temperature of about $7.4 \mathrm{~K}$. Consequently the $\mathrm{J}_{\mathrm{op}}$ is $64 \%$ of the $\mathrm{J}_{\mathrm{c}}$ of a free standing wire. For a conductor with $50 \mathrm{kA} \mathrm{I}_{\mathrm{c}}$ at $17 \mathrm{~T}$ and $4.5 \mathrm{~K}$, the ceramic cross section is about $60 \mathrm{~mm}^{2}$ for the moderate strands, corresponding to a total strand cross section of $300 \mathrm{~mm}^{2}$. For the A-wire, the total strand cross section is about $67 \mathrm{~mm}^{2}$.

\section{B. Cable layouts}

In $\mathrm{R} \& \mathrm{~W}$ cables the strands should be located as close as possible to the cable mid-plane, in order to keep the bending strain during winding as small as possible. Therefore all the considered cables are flat and have a large aspect ratio (see Table IV). In addition to the common Rutherford cable, other types of flat cables, composed of twisted pairs and triplets have been studied. In the cable name, the first number indicates the number of twist stages and the second one (or two) indicates the sub-cable pattern.

A Roebel bar made of rectangular wires (two different aspect ratio were considered) is also discussed; the main advantage of this configuration is that low void fraction can be obtained without compaction; for this reason the Roebel bar is particularly suitable for Bi-2212 wires, which are very sensitive to deformation during compaction [37].

To evaluate these cables, the following criteria are considered during the selection process.

- Compaction rate: the cable should be compacted as much as possible to avoid degradation with cycling load [38].

- Cable thickness: the cable should be thin enough to limit the bending strain during winding

- Cable width: the cable should be narrow enough to limit the in-plane bending strain during turn-to-turn transitions (orthocyclic winding method).

\section{Compaction rate and void fraction}

In Rutherford cables the compaction rate (or packing factor) is the sum of the cross-sectional area of all the strands divided by the area of the die used for compaction. A rate of 0.78 is the minimum achievable, corresponding to no deformation on the strands; the void fraction is then $22 \%$. In NbTi Rutherfod cables the compaction rate is between 0.88 and 0.92 . For Bi2212 Rutherford cables, it has been reported [38] that the 
Table V

PARAMETERS OF SELECTED CABLES

\begin{tabular}{llllll}
\hline \hline Cable configuration & Wire & Wire $\boldsymbol{\varphi}$ & No. of & Cable & Cable width \\
& type & $(\mathbf{m m})$ & strands & thickness (mm) & (mm) \\
\hline 2-layer Roebel bar $(\mathrm{a}=2)$ & M-wire & $1 \times 2$ & 148 & 8 & 37 \\
Rutherford cable $\left(\mathrm{T}_{\mathrm{cs}}=7.4 \mathrm{~K}\right)$ & A-wire & 1.5 & 37 & 3 & 23.0 \\
Rutherford cable $\left(\mathrm{T}_{\mathrm{cs}}=10 \mathrm{~K}\right)$ & A-wire & 1.5 & 49 & 3 & 29.8 \\
\hline \hline
\end{tabular}

compaction rate should be $<0.85$. The reason is that, as measured in [37], $I_{c}$ in Bi2212 wires is very sensitive to indentation.

For the last four conductors in Table. IV, the void fraction after compaction of 0.85 is still very large, and they might suffer from $\mathrm{J}_{\mathrm{c}}$ degradation by cycling load, because the strands would have plenty of space to move under transverse electromagnetic forces. If much larger compaction rate is applied in order to reduce the void fraction, they might suffer from $J_{c}$ degradation by wire indentation due to compaction. Therefore these conductors are unlikely to be selected.

\section{$D$. Width and thickness of cable}

For CS coil with inner radius of $1 \mathrm{~m}$, the maximum strain range of $\pm 0.4 \%$ results in a maximum allowable cable thickness of $8 \mathrm{~mm}$, assuming the strands are fully bonded. This is a conservative assumption, because it was found that in Bi2212 Rutherford cables the strands were free to move one with respect to the others [39] under bending.

Regarding the cable width, the limit comes from the in-plane bending at the turn-to-turn cross over. For a winding radius of $1 \mathrm{~m}$ and a turn-to-turn transition length of $1 / 5$ of the circumference, the width should be less than $40 \mathrm{~mm}$ in order to keep the strain below $0.4 \%$.

\section{E. Cable selection}

A first selection is carried out based on the cable dimensions and available strand diameters. Fig. 3 shows the nominal width and thickness (before compaction) of the cables as function of the strand diameter. The yellow rectangle shows the region with strand diameter between $0.8 \mathrm{~mm}$ and $1.5 \mathrm{~mm}$ (currently available) and with cable thickness $<8 \mathrm{~mm}$, and cable width $<40 \mathrm{~mm}$. A cable design should be discarded if the corresponding cable width (dashed line) and cable thickness (solid line) versus strand diameter are not present in the yellow rectangle at the same time.

For A-wires (Fig. 3 left), because of the high $\mathrm{J}_{\mathrm{c}}$, almost all the layouts can be selected. For example a Rutherford cable (the thinnest of all options) with a wire of $1.2 \mathrm{~mm}$ diameter, would have a cross section of $3.0 \mathrm{~mm} \times 28.5 \mathrm{~mm}$.

For cables with M-wires, the width become a critical problem since the number of wires increase a lot. Only the 2layer Roebel bar can be selected, with a wire slightly bigger than the common ones $\left(2 \mathrm{~mm}^{2}\right)$.

To summarize: the remarkable improvement of the $\mathrm{J}_{\mathrm{c}}$ in $\mathrm{Bi}-$ 2212 wires makes it possible to design an R\&W cable. In the most favorable case $\left(\mathrm{J}_{\mathrm{c}}\right.$ of $5927 \mathrm{~A} / \mathrm{mm}^{2}$ at $4.5 \mathrm{~K}$ and $17 \mathrm{~T}$;

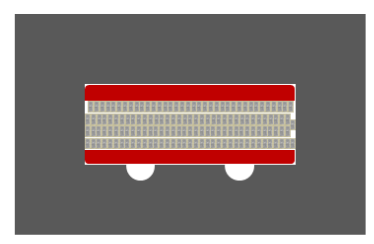

2-layer Roebel bar 148 M-wires, $1 \mathrm{~mm} \times 2 \mathrm{~mm},\left(296 \mathrm{~mm}^{2}\right)$

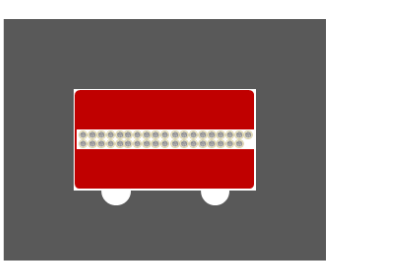

525 wires, $\Phi 0.8 \mathrm{~mm},\left(264 \mathrm{~mm}^{2}\right)$

Rutherford cable

37 A-wires, $\Phi 1.5 \mathrm{~mm},\left(65 \mathrm{~mm}^{2}\right)$

Fig. 4 Selected cable configurations (the left two figures) and schemes of the conductors with both jacket (not in real scale) and additional copper protection (see section IV). Additional cooling channel might be needed for some conductors like the Roebel bar, since the void in cable region is too small. The right figure is a round $\mathrm{Bi}-2212 \mathrm{CICC}$.

corresponding to $\mathrm{J}_{\mathrm{e}}$ of $1185 \mathrm{~A} / \mathrm{mm}^{2}$ ), a very simple and compact Rutherford is a possible option. Considering a very modest wire with $\mathrm{J}_{\mathrm{c}}$ of $1317 \mathrm{~A} / \mathrm{mm}^{2}$ at $4.5 \mathrm{~K}$ and $17 \mathrm{~T}$ (achieved by all densified wires), only the Roebel bars are possible options. If the performance of the wires is in between the two, some of the other options would be also feasible, like the 2layer coaxial Rutherford, which consist simply in wrapping the Rutherford cable with another layer of wires. The twist pitches of the two layers should be chosen to minimize the inductance mismatch between the two layers, and thus uniform current distribution during current ramps [40]. Other cable configurations with high initial void fraction are not as appealing as the former ones.

\section{OPERATING ISSUES IN CENTRAL SOLENOID}

Two cable designs are selected for further discussion because of their dimensions, the low void fraction and the low compaction rate: Roebel bar with $\mathrm{M}$-wire and Rutherford cable with A-wire. One more cable with higher $\mathrm{T}_{\mathrm{cs}}(10 \mathrm{~K}$ instead of $7.4 \mathrm{~K}$ ) is also designed with A-wire. Table $\mathrm{V}$ lists the selected design parameters and sketches of the cross section are shown in Fig. 4. In Fig. 4, a round Bi-2212 CICC is also shown for comparison [36].

\section{A. Transverse stress}


When the Central Solenoid is charged, the magnetic field in vertical direction and the current in circumferential direction result into radial outward force on the cable. The outermost wires in the cable will withstand the maximum force by accumulating the force from all the other wires.

Table. V shows the estimation of average transverse stress for the optimized cable configurations. Katagiri et al [26] reported an experiment on $\mathrm{Bi}-2212$ wire, which shows a transverse stress limit for irreversible $\mathrm{J}_{\mathrm{c}}$ degradation ranging from $9 \mathrm{MPa}$ to $20 \mathrm{MPa}$; similar low values were measured also in Bi-2212 with $\mathrm{AgZr}$ matrix [41]. This could be a harsh restriction for both $\mathrm{R} \& \mathrm{~W}$ and $\mathrm{W} \& \mathrm{R}$ cable. It should be noted that in these two papers, Bi-2212 also shows poor property against tension. Whereas as mentioned above, modern Bi-2212 wires are made with strong $\mathrm{Ag}-\mathrm{Mg}$ alloy as sheath and filaments are densified. As a consequence, the transverse stress limit could also increase. However, there are no published values for critical transverse stress on state-to-art wires. It would be very valuable to measure the critical current retention under transverse pressure in the state-of-art Bi-2212 wires.

On the other hand, Dietderich et al [42] has measured a much higher stress limit of $60 \mathrm{MPa}$ on a Rutherford cable in a fiberglass-reinforced epoxy matrix. Bi-2223 tapes, which have similar tension behavior of $\mathrm{Bi}-2212$ wires, can withstands transverse pressure of about $70 \mathrm{MPa}$ [43]. In round $\mathrm{Nb}_{3} \mathrm{Sn}$ wires it was found that the degradation of $\mathrm{J}_{\mathrm{c}}$ happens already at few $\mathrm{MPa}$, while in hydrostatic conditions, for example if the wire is surrounded by resin, as is the case of impregnated cables, the critical stress is much higher (40 MPa) [44]. This makes the Roebel bar with rectangular shape more attractive.

In the Bi-2212 round conductor (which used a low current wire, comparable to M-wire) for CFTER the stress can be estimated at about $45 \mathrm{MPa}$ [36]. Therefore in flat cables the transverse stress would be about two times lower than in round conductors. For comparison the accumulated transverse stress in ITER $\mathrm{Nb}_{3} \mathrm{Sn}$ conductors (900 strands, $68 \mathrm{kA}, 11.8 \mathrm{~T}$ ) is about $37 \mathrm{MPa}$ [45].

\section{B. Stability}

The stability of the conductor against various types of perturbations was of particular importance in the development of LTS cables, because LTS materials have low stability (the reason is that $J_{c}$ decreases very rapidly with temperature). In HTS $J_{c}$ decreases slowly with temperature, thus are expected to be more stable against any type of perturbation.

A simple thermal-hydraulic model analysis with CryoSoft THEA [46] is used to calculate the energy margin and hot spot temperature in the case of quench for Bi-2212 conductor. The model consists of the Bi-2212 cable (all the wires are considered homogeneous in thermal and electrical), a stainless steel jacket (similar amount of steel is assumed as ITER CS conductor [47], although for a DEMO reactor in which HTS is most likely to be employed, it would be much more [48]) and forced flow critical helium (operating pressure is 6 bar, with pressure drop $1 \mathrm{bar} / \mathrm{km}$ [49]) in the void. The cable is composed of Bi-2212 ceramic ( $n$ value $=30)$, silver $(\mathrm{RRR}=220)$, $\mathrm{AgMg}(\mathrm{RRR}=5)[50,51]$ and copper $(\mathrm{RRR}=100)$. Based on a recent thermal-hydraulic test on $\mathrm{Nb}_{3} \mathrm{Sn}$ cable-in-conduit conductor (CICC) at SPC, the cable-jacket thermal resistance is assumed to be $0.01 \mathrm{Km} / \mathrm{W}$ for conductor with M-wires and $0.02 \mathrm{Km} / \mathrm{W}$ for conductor with A-wire, since in the former the contact area is about twice. For quench simulation, $0.1 \mathrm{~V}$ is assumed as the detection voltage, $1.1 \mathrm{~s}$ is assumed for quench protection system (QPS) reaction and $20 \mathrm{~s}$ is assumed as the discharge time constant [52, 53]. A heat disturbance is deposited into the cable along $0.1 \mathrm{~m}$ and during $0.1 \mathrm{~s}$.

Fig. 5 shows the calculated stability margin of the conductors (in $\mathrm{mJ} / \mathrm{cm}^{3}$ ) as function of copper cross section. The conductor's stability is already comparable or larger than the one of ITER $\mathrm{Nb}_{3} \mathrm{Sn}$ CICC $\left(>200 \mathrm{~mJ} / \mathrm{cm}^{3}\right)$ even without using any additional copper [54]; for comparison, in ITER the energy for mechanical disturbances was estimated at $15 \mathrm{~mJ} / \mathrm{cm}^{3}$ and the energy from AC losses between 80 and $120 \mathrm{~mJ} / \mathrm{cm}^{3}$ [54]. Therefore a Bi2212 cable could withstand higher transient thermal loads than an $\mathrm{Nb}_{3} \mathrm{Sn}$ cable.

\section{Quench protection material}

Regarding quench protection, the cross section and the electrical conductivity of the metal in parallel with the superconductor should be large enough to keep the hot spot temperature below a reasonable value. Using the model described in the previous section, the hot spot temperature is plotted as a function of the copper cross section in Fig. 5. It is found that $200 \mathrm{~mm}^{2}$ copper are enough to reduce the hot spot temperature to a reasonable level in M-wire cables. In A-wire cables, the copper cross section should be at least $400 \mathrm{~mm}^{2}$, because the amount of silver matrix is now lower. A higher $T_{c s}$,

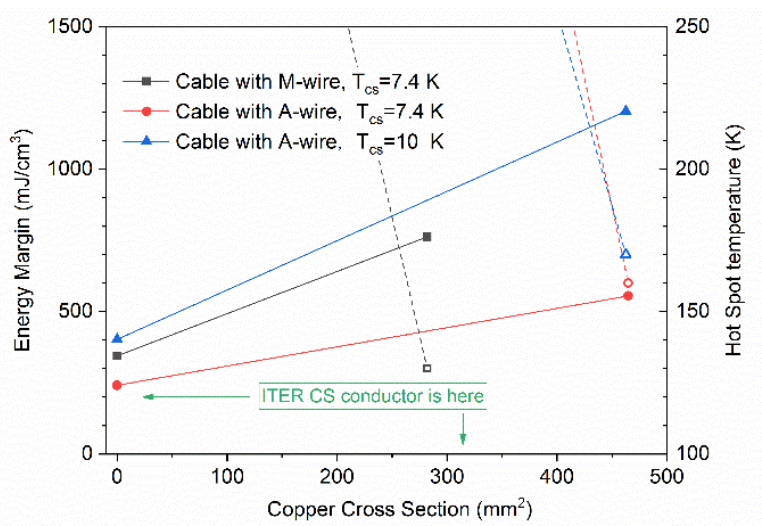

Fig. 5 Energy margin evaluating stability (filled symbols and solids lines) and hot spot temperature evaluating quench (open symbols and dash lines) as function of copper cross section.

Table VI

THERMAL CONTRACTION OF BI-2212 WIRE AND POSSIBLE JACKET MATERIALS FROM ROOM TEMPERATURE TO $4 \mathrm{~K}$

\begin{tabular}{ll} 
Material & $\Delta \mathbf{L} / \mathbf{L}(\%)$ \\
\hline Bi-2212 wire ${ }^{[54]}$ & -0.284 \\
Stainless steel 316 ${ }^{[55]}$ & -0.297 \\
Ni80Cr $^{[56]}$ & -0.229 \\
Inconel X750 $^{[57]}$ & -0.218 \\
\hline \hline
\end{tabular}


i.e. more superconducting strands, is of little use for controlling hot spot temperature. Large amount of high conductivity metal is always needed: copper can be introduced as a flat-highly-compacted cable; to reduce losses in the copper, thin wire with $\mathrm{Cr}$ or $\mathrm{Ni}$ coating should be used. Another option is to use a solid mixed 95\% Cu and 5\% Cu-Ni matrix [10]. One advantage of the $\mathrm{R} \& \mathrm{~W} \mathrm{Bi}-2212$ conductor is that copper can be included in the cable, while in W\&R conductor the copper should not get in contact with oxygen during the heat treatment.

\section{Cable Jacket}

The CS magnet is composed of several solenoid modules; at operation the hoop loads and vertical loads are very large and are supported by a thick jacket. For an R\&W Bi-2212 conductor, the jacket is added after the heat treatment, thus the choice of materials is wide. On the other hand, the different thermal contraction of jacket and strands during cooling will bring addition thermal strain in the strands. Therefore, the best jacket material should have thermal expansion close to the one of Bi-2212. Table VI shows the thermal contraction of some materials as well as $\mathrm{Bi}-2212$ wire from room temperature to 4.2 K [55-58]. Stainless steel 316 is a very good choice because the thermal contraction is very close to the one of $\mathrm{Bi}-2212$ wire. The other two alloys Inconel X750 and Ni80Cr are considered as structural material for $\mathrm{W} \& \mathrm{R} \mathrm{Bi}-2212$ conductor but will result in tension of about $0.06 \%$. Indeed, in the case of $W \& R$ conductor, although bending strain is eliminated, cooling down from the heat treatment temperature $(\sim 1100 \mathrm{~K})$ to operating temperature $(\sim 4 \mathrm{~K})$ might introduce higher thermal strain, as in the case if ITER conductor [59]. The dimensioning of the jacket cross section should be studied during the magnet and winding pack design, therefore will not be further discussed here.

\section{SUMMARY}

Various $50-\mathrm{kA}$ R\&W flat cables with round or rectangular wires have been studied. Two hypothetical strands were considered with conservative $\mathrm{J}_{\mathrm{c}}$ (M-wire, modest $\mathrm{J}_{\mathrm{c}}$ ) and ambitious $\mathrm{J}_{\mathrm{c}}$ (A-wire). With $20 \% \mathrm{~J}_{\mathrm{c}}$ degradation, a sufficient axial strain range from $-0.4 \%$ to $0.4 \%$ is available for bending. With M-wire (modest current density achieved by all state-ofart wires), Roebel bar cable. With A-wire (very high current density), even Rutherford cable becomes available. Roebel bar cable has the highest filling factor and is free from compaction, therefore decreases the risk to degrade $I_{c}$ of cable by indentation during compaction.

$\mathrm{R} \& \mathrm{~W}$ flat conductor can be wound after reaction, allowing many choices of jacket and insulation materials. A proper jacket material should be strong and have comparable thermal contraction with $\mathrm{Bi}-2212$ wire to reduce the thermal strain during cooling down, for example stainless steel 316.

Bi-2212 conductor is quite stable, but for quench protection additional low resistance material should be added; copper can be used in $\mathrm{R} \& \mathrm{~W} \mathrm{Bi}-2212$ conductor; the cross section should be at least $200 \mathrm{~mm}^{2}$.

The transverse load in flat cable is much smaller than in the round CICC. But for cable with A-wire, the transverse stress may still be above the limit. The critical transverse pressure should be measured on state-of-art $\mathrm{Bi}-2212$ wires with better mechanical properties.

Prototypes of these $\mathrm{R} \& \mathrm{~W} \mathrm{Bi}-2212$ conductor concepts should be manufactured in future to verify the engineering feasibility and measure the properties, especially for relatively new concepts, i.e. 2-layer Rutherford and Roebel bar conductors.

\section{ACKONWLEDGEMENT}

Rui Kang gratefully acknowledges the financial support from China Scholarship Council and the help from Dr. R. Wesche for scaling law.

\section{REFERENCE}

[1] J. Jiang, W. L. Starch, M. Hannion, F. Kametani, U. P. Trociewitz, E. E. Hellstrom, and D. C. Larbalestier, "Doubled critical current density in Bi-2212 round wires by reduction of the residual bubble density," Superconductor Science \& Technology, vol. 24, no. 8, Aug, 2011.

[2] D. C. Larbalestier, J. Jiang, U. P. Trociewitz, F. Kametani, C. Scheuerlein, M. Dalban-Canassy, M. Matras, P. Chen, N. C. Craig, P. J. Lee, and E. E. Hellstrom, "Isotropic round-wire multifilament cuprate superconductor for generation of magnetic fields above 30 T," Nat Mater, vol. 13, no. 4, pp. 37581, Apr, 2014.

[3] D. Clazynski, "Review of Nb3Sn conductors for ITER," Fusion Engineering and Design, vol. 82, no. 5-14, pp. 488-497, Oct, 2007.

[4] J. G. Qin, Y. Wu, J. G. Li, C. Dai, F. Liu, H. J. Liu, P. H. Liu, C. S. Li, Q. B. Hao, C. Zhou, and S. Liu, "Manufacture and Test of Bi-2212 Cable-in-Conduit Conductor," Ieee Transactions on Applied Superconductivity, vol. 27, no. 4, pp. 5, Jun, 2017.

[5] A. Godeke, D. Cheng, D. R. Dietderich, C. D. English, H. Felice, C. R. Hannaford, S. O. Prestemon, G. Sabbi, R. M. Scanlan, Y. Hikichi, J. Nishioka, and T. Hasegawa, "Development of Wind-and-React Bi-2212 Accelerator Magnet Technology," IEEE Transactions on Applied Superconductivity, vol. 18, no. 2, pp. 516-519, 2008.

[6] T. M. Shen, P. Li, J. Y. Jiang, L. Cooley, J. Tompkins, D. McRae, and R. Walsh, "High strength kiloampere Bi2Sr2CaCu2Ox cables for high-field magnet applications," Superconductor Science \& Technology, vol. 28, no. 6, pp. 10, Jun, 2015.

[7] P. H. Liu, Z. H. Mao, J. G. Qin, C. Dai, H. Jin, L. F. Li, K. Wang, H. Ji, and S. Liu, "Research on the Mechanical Properties of Jacket Used for Bi-2212 Cable-In-Conduit Conductor," IEEE Transactions on Applied Superconductivity, vol. 27, no. 4, pp. 4, Jun, 2017.

[8] R. Gupta, M. Anerella, J. Cozzolino, J. Escallier, G. Ganetis, A. Ghosh, M. Harrison, A. Jain, A. Marone, J. Muratore, B. Parker, W. Sampson, and P. Wanderer, "R\&D for accelerator magnets with react and wind high temperature superconductors," IEEE Transactions on Applied 
Superconductivity, vol. 12, no. 1, pp. 75-80, Mar, 2002.

[9] K. Sedlak, P. Bruzzone, X. Sarasola, B. Stepanov, and R. Wesche, "Design and R\&D for the DEMO Toroidal Field Coils Based on Nb3Sn React and Wind Method," IEEE Transactions on Applied Superconductivity, vol. 27, no. 4, pp. 5, Jun, 2017. [10] R. Wesche, N. Bykovsky, X. Sarasola, K. Sedlak, B. Stepanov, D. Uglietti, and P. Bruzzone, "Central solenoid winding pack design for DEMO," Fusion Engineering and Design, vol. 124, pp. 82-85, Nov, 2017.

[11] Y. B. Huang, H. P. Miao, S. Hong, and J. A. Parrell, "Bi2212 Round Wire Development for High Field Applications," IEEE Transactions on Applied Superconductivity, vol. 24, no. 3, pp. 5, Jun, 2014.

[12] A. Malagoli, V. Braccini, M. Vignolo, X. Chaud, and M. Putti, "Groove-rolling as an alternative process to fabricate Bi2212 wires for practical applications," Superconductor Science \& Technology, vol. 27, no. 5, pp. 6, May, 2014.

[13] A. Leveratto, V. Braccini, D. Contarino, C. Ferdeghini, and A. Malagoli, "New concept for the development of Bi2212 wires for high-field applications," Superconductor Science \& Technology, vol. 29, no. 4, pp. 5, Apr, 2016.

[14] A. Leveratto, V. Zunino, I. Pallecchi, V. Braccini, C. Ferdeghini, and A. Malagoli, "Measurements of Magnetic Field and Temperature Dependence of the Critical Current in Bi-2212 Superconducting Wires," IEEE Transactions on Applied Superconductivity, vol. 27, no. 4, Jun, 2017.

[15] J. Y. Jiang, G. Bradford, S. I. Hossain, M. D. Brown, J. Cooper, E. Miller, Y. B. Huang, H. P. Miao, J. A. Parrell, M. White, A. Hunt, S. Sengupta, R. Revur, T. M. Shen, F. Kametani, U. P. Trociewitz, E. E. Hellstrom, and D. C. Larbalestier, "High-Performance Bi-2212 Round Wires Made With Recent Powders," IEEE Transactions on Applied Superconductivity, vol. 29, no. 5, Aug, 2019.

[16] T. Hasegawa, N. Ohtani, T. Koizumi, Y. Aoki, S. Nagaya, N. Hirano, L. Motowidlo, R. S. Sokolowski, R. M. Scanlan, D. R. Dietderich, and S. Hanai, "Improvement of superconducting properties of $\mathrm{Bi}-2212$ round wire and primary test results of large capacity Rutherford cable," IEEE Transactions on Appiled Superconductivity, vol. 11, no. 1, pp. 3034-3037, 2001.

[17] J. M. Rey, A. Allais, J. L. Duchateau, P. Fazilleau, J. M. Gheller, R. Le Bouter, O. Louchard, L. Quettier, and D. Tordera, "Critical Current Measurement in HTS Bi2212 Ribbons and Round Wires," Ieee Transactions on Applied Superconductivity, vol. 19, no. 3, pp. 3088-3093, Jun, 2009.

[18] V. Lombardo, E. Barzi, D. Turrioni, and A. V. Zlobin, "Critical Currents of YBa2Cu3O7-delta Tapes and $\mathrm{Bi} 2 \mathrm{Sr} 2 \mathrm{CaCu} 2 \mathrm{Ox}$ Wires at Different Temperatures and Magnetic Fields," IEEE Transactions on Applied Superconductivity, vol. 21, no. 3, pp. 3247-3250, Jun, 2011.

[19] Y. Zhang, S. Johnson, G. Naderi, M. Chaubal, A. Hunt, and J. Schwartz, "High critical current density $\mathrm{Bi} 2 \mathrm{Sr} 2 \mathrm{CaCu} 2 \mathrm{Ox} / \mathrm{Ag}$ wire containing oxide precursor synthesized from nano-oxides," Superconductor Science \& Technology, vol. 29, no. 9, Sep, 2016.

[20] H. J. Liu, H. J. Ma, F. Liu, Y. Shi, J. G. Qin, Y. Wu, J. G. Li, and L. Lei, "Experimental Study on Bi-2212 Cable-in-
Conduit Conductor," Ieee Transactions on Applied Superconductivity, vol. 28, no. 4, Jun, 2018.

[21] R. Wesche, "Temperature dependence of critical currents in superconducting Bi-2212/Ag wires," Physica C: Superconductivity, vol. 246, no. 1-2, pp. 186-194, 1995.

[22] R. Herzog, R. Wesche, and P. Bruzzone, "Field and temperature dependence of critical currents in industrially manufactured high-Tc wires and tapes," Journal of Physics: Conference Series, vol. 97, pp. 012208, 2008.

[23] J. W. Ekin, D. K. Finnemore, Q. Li, J. Tenbrink, and W. Carter, "EFFECT OF AXIAL STRAIN ON THE CRITICAL CURRENT OF AG-SHEATHED BIBASED SUPERCONDUCTORS IN MAGNETIC-FIELDS UP TO 25T," Applied Physics Letters, vol. 61, no. 7, pp. 858-860, Aug 17, 1992.

[24] B. tenhaken, H. H. J. Tenkate, and J. Tenbrink, "Compressive and Tensile Axial Strain Reduced Critical Currents in Bi-2212 Conductors," IEEE Transactions on Applied Superconductivity, vol. 5, no. 2, pp. 1298-1301, Jun, 1995.

[25] B. tenHaken, A. Godeke, H. J. Schuver, and H. H. J. tenKate, "Descriptive model for the critical current as a function of axial strain in Bi-2212/Ag wires," Ieee Transactions on Magnetics, vol. 32, no. 4, pp. 2720-2723, Jul, 1996.

[26] K. Katagiri, H. S. Shin, Y. Shoji, N. Ebisawa, K. Watanabe, K. Noto, T. Okada, M. Hiraoka, and S. Yuya, "Tensile strain transverse compressive stress dependence of critical current in Ag-sheathed $\operatorname{Bi}(2212)$ 7-core superconducting wires," Cryogenics, vol. 36, no. 6, pp. 491494, Jun, 1996.

[27] M. Sugano, K. Itoh, and T. Kiyoshi, "Strain dependence of critical current in Bi2212W \& R wires under magnetic field up to 30 T," IEEE Transactions on Applied Superconductivity, vol. 16, no. 2, pp. 1039-1042, Jun, 2006.

[28] X. F. Lu, N. Cheggour, T. C. Stauffer, C. C. Clickner, L. F. Goodrich, U. Trociewitz, D. Myers, and T. G. Holesinger, "Electromechanical Characterization of Bi-2212 Strands," IEEE Transactions on Applied Superconductivity, vol. 21, no. 3, pp. 3086-3089, Jun, 2011.

[29] N. Cheggour, X. F. Lu, T. G. Holesinger, T. C. Stauffer, J. Jiang, and L. F. Goodrich, "Reversible effect of strain on transport critical current in $\mathrm{Bi} 2 \mathrm{Sr} 2 \mathrm{CaCu} 2 \mathrm{O} 8+x$ superconducting wires: a modified descriptive strain model," Superconductor Science \& Technology, vol. 25, no. 1, Jan, 2012.

[30] A. Godeke, M. H. C. Hartman, M. G. T. Mentink, J. Jiang, M. Matras, E. E. Hellstrom, and D. C. Larbalestier, "Critical current of dense Bi-2212 round wires as a function of axial strain," Superconductor Science \& Technology, vol. 28, no. 3, pp. 5, Mar, 2015.

[31] R. Bjoerstad, C. Scheuerlein, M. O. Rikel, A. Ballarino, L. Bottura, J. Jiang, M. Matras, M. Sugano, J. Hudspeth, and M. Di Michiel, "Strain induced irreversible critical current degradation in highly dense Bi-2212 round wire," Superconductor Science \& Technology, vol. 28, no. 6, pp. 8, Jun, 2015. 
[32] M. Brown, E. Bosque, D. McRae, R. P. Walsh, J. Jiang, E. E. Hellstrom, Y. Kim, U. Trociewitz, A. Otto, D. C. Larbalestier, and Iop, "Tensile properties and critical current strain limits of reinforced Bi-2212 conductors for high field magnets," Advances in Cryogenic Engineering - Materials, IOP Conference Series-Materials Science and Engineering, Bristol: Iop Publishing Ltd, 2017.

[33] C. Dai, J. G. Qin, B. Liu, P. H. Liu, Y. Wu, A. Nijhuis, C. Zhou, C. S. Li, Q. B. Hao, and S. Liu, "Uniaxial Strain Induced Critical Current Degradation of Ag-Sheathed Bi-2212 Round Wire," IEEE Transactions on Applied Superconductivity, vol. 28, no. 3, pp. 4, Apr, 2018.

[34] A. Nijhuis, R. P. P. van Meerdervoort, H. J. G. Krooshoop, W. A. J. Wessel, C. Zhou, G. Rolando, C. Sanabria, P. J. Lee, D. C. Larbalestier, A. Devred, A. Vostner, N. Mitchell, Y. Takahashi, Y. Nabara, T. Boutboul, V. Tronza, S. H. Park, and $\mathrm{W}$. Yu, "The effect of axial and transverse loading on the transport properties of ITER Nb3Sn strands," Superconductor Science \& Technology, vol. 26, no. 8, Aug, 2013.

[35] P. Bruzzone, K. Sedlak, X. Sarasola, B. Stepanov, D. Uglietti, R. Wesche, L. Muzzi, and A. della Corte, "A Prototype Conductor by React\&WIND Method for the EUROfusion DEMO TF Coils," Ieee Transactions on Applied Superconductivity, vol. 28, no. 3, Apr, 2018.

[36] R. Kang, J. Zheng, Y. Song, L. Wang, and X. He, "Stability study of Bi-2212 conductor based on perturbation spectrum for hybrid superconducting magnet," International Journal of Energy Research, 2017.

[37] J. G. Qin, C. Dai, Q. L. Wang, P. H. Liu, B. Liu, F. Liu, Y. Wu, C. Zhou, Q. B. Hao, C. S. Li, and S. Liu, "Impact of Indentation on the Critical Current of Bi2212 Round Wire," IEEE Transactions on Applied Superconductivity, vol. 26, no. 4, pp. 5, Jun, 2016.

[38] P. Bruzzone, "Review of Design Aspects for High Current Nb3Sn Conductors," IEEE Transactions on Applied Superconductivity, vol. 21, no. 3, pp. 2036-2041, Jun, 2011.

[39] T. Hasegawa, J. Nishioka, N. Ohtani, Y. Hikichi, R. Scanlan, R. Gupta, N. Hirano, and S. Nagaya, "12 kA HTS Rutherford Cable," IEEE Transactions on Appiled Superconductivity, vol. 14, no. 2, pp. 1066-1069, 2004.

[40] P. Bruzzone, "30 years of conductors for fusion: A summary and perspectives," IEEE Transactions on Applied Superconductivity, vol. 16, no. 2, pp. 839-844, Jun, 2006.

[41] K. Katagiri, K. Kasaba, Y. Shoji, T. Takahashi, K. Watanabe, K. Noto, T. Okada, M. Hiraoka, and S. Yuhya, "Tensile strain transverse compressive stress dependence of critical current in $\mathrm{Bi}(2212)$ superconducting tapes with $\mathrm{Zr}$ reinforced Ag sheath," Cryogenics, vol. 38, no. 3, pp. 283-288, Mar, 1998.

[42] D. R. Dietderich, R. M. Scanlan, T. Hasegawa, Y. Aoki, R. S. Sokolowski, and L. R. Motowidlo, "Critical current variation as a function of transverse stress of $\mathrm{Bi}-2212$ rutherford cables," IEEE Transactions on Applied Superconductivity, vol. 11, no. 1, pp. 3577-3579, Mar, 2001.

[43] C. Scheuerlein, R. Bjoerstad, A. Grether, M. O. Rikel, J. Hudspeth, M. Sugano, A. Ballarino, and L. Bottura, "Comparison of Electromechanical Properties and Lattice
Distortions of Different Cuprate High-Temperature Superconductors," IEEE Transactions on Applied Superconductivity, vol. 26, no. 3, Apr, 2016.

[44] G. Mondonico, B. Seeber, A. Ferreira, B. Bordini, L. Oberli, L. Bottura, A. Ballarino, R. Flukiger, and C. Senatore, "Effect of quasi-hydrostatical radial pressure on I-c of Nb3Sn wires," Superconductor Science \& Technology, vol. 25, no. 11, Nov, 2012.

[45] J. H. Schultz, T. Antaya, J. Feng, C. Y. Gung, N. Martovetsky, J. V. Minervini, P. Michael, A. Radovinsky, and P. Titus, "The ITER Central Solenoid," 21st IEEE/NPSS Symposium on Fusion Engineering - SOFE 05, pp. 142-145, 2006.

[46] L. Bottura, C. Rosso, and M. Breschi, "A general model for thermal, hydraulic and electric analysis of superconducting cables," Cryogenics, vol. 40, no. 8-10, pp. 617-626, Aug-Oct, 2000.

[47] J. H. Schultz, T. Antaya, J. Feng, C. Y. Gung, N. Martovetsky, J. V. Minervini, P. Michael, A. Radovinsky, and P. Titus, "The ITER Central Solenoid," in 21st IEEE/NPSS Symposium on Fusion Engineering - SOFE 05, 2006, pp. 142145.

[48] R. Wesche, X. Sarasola, K. Sedlak, N. Bykovsky, B. Stepanov, D. Uglietti, and P. Bruzzone, "DEMO Central Solenoid Design Based on the Use of HTS Sections at Highest Magnetic Field," IEEE Transactions on Applied Superconductivity, vol. 28, no. 3, Apr, 2018.

[49] A. Dembkowska, M. Lewandowska, and X. Sarasola, "Thermal-Hydraulic Analysis of the DEMO CS Coil," IEEE Transactions on Applied Superconductivity, vol. 28, no. 4, pp. 1-5, Jun, 2018.

[50] P. Li, L. Ye, J. Jiang, and T. Shen, "RRR and thermal conductivity of Ag and Ag-0.2 wt.\% Mg alloy in Ag/Bi-2212 wires."

[51] M. Bonura, F. Avitabile, C. Barth, J. Jiang, D. C. Larbalestier, A. Fête, A. Leo, L. Bottura, and C. Senatore, "Very-high thermal and electrical conductivity in overpressure-processed

$\mathrm{Bi}<$ sub $>2</$ sub $>\mathrm{Sr}<$ sub $>2</$ sub $>\mathrm{CaCu}<$ sub $>2</$ sub $>\mathrm{O}<$ sub $>$ $8+\mathrm{x}</$ sub $>$ wires," Materials Research Express, 2018.

[52] V. Corato, R. Bonifetto, P. Bruzzone, D. Ciazynski, M. Coleman, E. Galo, and e. al., "Common operating values for DEMO magnets design for 2016," 2016.

[53] A. Torre, D. Ciazynski, and L. Zani, "EU-DEMO TF and CS Magnet Systems Design and Analyses Performed at CEA," IEEE Transactions on Applied Superconductivity, vol. 27, no. 4, Jun, 2017.

[54] C. Marinucci, L. Savoldi, and R. Zanino, "Stability analysis of the ITER TF and CS conductors using the code Gandalf," IEEE Transactions on Applied Superconductivity, vol. 9, no. 2, pp. 612-615, Jun, 1999.

[55] M. Sugano, K. I. Oh, A. Nyilas, and T. Kiyoshi, "Irreversible behavior of thermal expansion in Bi2212 composite wire at low temperature," Physica CSuperconductivity and Its Applications, vol. 445, pp. 751-755, Oct 1, 2006.

[56] D. Mann, LNG Materials \& Fluids: A User's Manual of 
Property Data in Graphic Format, NATIONAL STANDARD REFERENCE DATA SYSTEM, 1977.

[57] R. J. Corruccini, and J. J. Gniewek, Thermal Expansion of Technical Solids at Low Temperatures: A Compilation From the Literature, 1961.

[58] E. W. Collings, F. J. Jelinek, J. C. Ho, and M. P. Mathur, "Magnetic and Thermal Properties of Stainless Steel and Inconel at Cryogenic Temperatures," pp. 159-173, 1977.

[59] D. Uglietti, K. Sedlak, R. Wesche, P. Bruzzone, L. Muzzi, and A. della Corte, "Progressing in cable-in-conduit for fusion magnets: from ITER to low cost, high performance DEMO," Superconductor Science and Technology, vol. 31, no. 5, pp. 055004, 2018. 